UNIVERSITY OF GOTHENBURG SCHOOL OF BUSINESS, ECONOMICS AND LAW

WORKING PAPERS IN ECONOMICS

No 513

\title{
Reference-dependent behaviour of paua (abalone) divers in New Zealand
}

$$
\text { by }
$$

Håkan Eggert and Viktoria Kahui

August 2011

ISSN 1403-2473 (print)

ISSN 1403-2465 (online)

Department of Economics

School of Business, Economics and Law at University of Gothenburg

Vasagatan 1, PO Box 640, SE 40530 Göteborg, Sweden

+46 31786 0000, +46317861326 (fax)

www.handels.gu.se info@handels.gu.se 


\title{
Reference-dependent behaviour of paua (abalone) divers in New Zealand.
}

\author{
Håkan Eggert $^{1}$ and Viktoria Kahui ${ }^{2}$
}

\begin{abstract}
We study dynamic labour supply using data on paua (abalone) divers in New Zealand. The divers face stable, flat prices per kilogram after each catch, but experience transitory wage changes due to varying weather and water conditions, and are free to vary their daily working hours and display an intermittent working pattern. We find non-linear wage elasticities, rejecting the standard neo-classical prediction. We explore potentially distorting factors, but find little evidence. Applying Kőszegi and Rabin's (2006) theory where workers have both income and hours targets could explain our result. In particular, our divers appear to be primarily guided by the hours target.
\end{abstract}

Keywords: labour supply, wage elasticity, income e target; reference-dependent preferences;

JEL codes: J01, J22;

\footnotetext{
${ }^{1}$ University of Gothenburg, Department of Economics, PO Box 640, Gothenburg, Sweden, Tel. +46 317864175; Hakan.Eggert@economics.gu.se

${ }^{2}$ University of Otago, Department of Economics, PO Box 56, Dunedin, New Zealand, Tel. +64 34795278, Fax +64 34798174; Viktoria.Kahui@otago.ac.nz
} 


\section{Introduction}

Dynamic models of labour supply predict a positive correlation between transitory wage changes and work hours, i.e. the intertemporal wage elasticity is determined by the substitution effect alone (Lucas and Rapping, 1969). Empirical estimates of life cycle models of labour supply often use individual panel data and find elasticities to be small (Card, 1994). However, relating annual changes in hours worked to annual changes in average hourly earnings are likely to be biased and require auxiliary assumptions relating to the persistence of wage shocks, formation of wage expectations, and it can be questioned whether annual wage changes are fully anticipated and purely transitory. In addition, it is a fact that workers rarely set their work hours (Dickens and Lundberg, 1993).

By studying workers that experience transitory wage changes and set their own hours, the above mentioned problems are reduced. Camerer et al. (1997) analysed three data sets of New York cab drivers and found significant and substantial negative elasticities, particularly for a group of inexperienced drivers. According to the authors these drivers made labour supply decisions one day at the time instead of substituting labour and leisure over several days, and set a daily income target and quit when reaching this target. The result is not unchallenged, and Oettinger (1999) held that overlooking the endogeneity of wage changes leads to severely downward biased elasticity estimates, which he demonstrated for stadium vendors at baseball games.

Goette et al (2004) also provided support for reference dependence preferences, while Farber (2005), also studying New York cab drivers, found that daily wages are not stable within days, and rejected an important role for reference-dependent preferences (Farber, 2008). Fehr and Goette (2007) found results in line with both 
perspectives. In a randomized field experiment with bicycle messengers, they established that the subjects did supply more labour with a transitory wage increase. However, a specific sub group with loss-averse individuals, identified in an additional experiment, responded with negative elasticity of effort per hour. Hence, if the supply effect dominates elasticities will be positive, while a dominating effort intensity reduction effect would lead to negative elasticities.

In response to the conflicting findings in the literature Köszegi and Rabin (from here on referred to as KR) (2006) developed a general theory of reference-dependent preferences that endogenizes reference targets based on the rational expectations of an outcome. By defining an individual's utility to depend on both a standard neoclassical consumption utility as well as on what they coin a gains-loss utility, they are able to combine the two theoretical strands in a general framework that allows to explain the predominant result of one or the other in specific economic circumstances. Crawford and Meng (2010) apply KR’s (2006) model to re-examine the labour supply decisions of New York City cabdrivers and find support in favour of the reference-dependent model. Abeler et al. (forthcoming) using an experiment also found support of reference-dependent preferences.

In this paper we use KR's (2006) theory of reference-dependent preferences, and in particular the assumption of both an income and an hours target, to explain our results of non-constant wage elasticities for paua (abalone) divers in three distinct areas in southern New Zealand. We derive our findings from analysing a unique data set of commercial paua (abalone) divers in southern New Zealand across three distinct areas. Paua is managed by an individual transferable quota (ITQ) system enabling contract divers to decide when and where to fish during a fishing year within a given area. The divers receive a stable, flat price per kilogram after each 
catch throughout the season, but experience transitory wage changes due to prevailing underwater visibility conditions and spatial resource abundance, and they are free to set their own hours. This provides an ideal background to study the substitution effect in isolation of the income effect, and to determine whether paua divers are behaving according to the predictions of neoclassical theory or in fact reveal reference-dependent preferences.

We establish a highly intermittent nature of the profession: the typical paua diver works approximately 3 to 4 months, spread more or less equally over the fishing year and undertakes 2 to 3 dives within each of those months, with no break to three days' break in between. He leaves in the morning (the profession is male dominated), searches for good patches, dives and collects, and returns to port the same day to deliver the catch to licensed fish receivers. Hence, the neoclassical prediction is that these divers should work long hours during days when transitory catch per unit of effort levels are high while they should quit early during days when hourly wages are low.

The Ministry of Fisheries in New Zealand requires divers to fill in a report after each diving trip (typically corresponding to a day of diving) and we have obtained three datasets (each corresponding to a distinct area) from 2001 to 2006 providing trip specific information on each individual diver including catch and effort data. The three datasets are analysed empirically. After controlling for weather conditions and seasonal effects on daily, monthly, and annual basis, we find labour elasticities close to zero. When we use a more flexible specification, which allows for non-constant wage elasticities, we find positive elasticities for low wages, zero elasticity at the average wage and negative elasticities for high wages across all three areas. Hence, on unexpected high wage days divers quite relatively earlier against the neoclassical 
prediction but during unexpected low wage days they quit earlier in line with the neoclassical prediction.

This apparent contradiction can be hosted within KR's (2006) model, where individuals' utility consists of two parts, consumption and gain-loss utility. The neoclassical model is a special case where gain-loss utility is zero, but unlike previous attempts to model reference dependence consumption utility is not assumed to be zero. The model makes a clear distinction between expected and unexpected wages and assumes that reference-dependence applies to both an income target and an hours target. These assumptions lead to the prediction that participation should increase when wages are expected to be high, reconciling the results of Oettinger (1999) and Camerer et al (1997). Further, unexpected high wages lead to workers reaching their income targets early and work short hours. For actual wages slightly below the expected level the hours target exerts a stronger influence on the decision to work pushing the wage elasticity close to zero. Our results indicate that it is reaching the hours target which is most influential for our data, implying that it is the first-reached target for low wages but the second reached target for high wages, unlike Crawford and Meng (2010) who found the second-reached target to be most influential on cab driver's decision to stop working throughout the wage interval. Both outcomes are possible within the KR theory. What matters is the relation between the targets and the optimal solution from the consumption utility alone. If the neoclassical optimal income and hours, i.e. solely from the consumption utility, are lower than the targets, the first-reached target becomes determinant (Crawford and Meng, 2010). The positive wage elasticities for very low wage realizations are possible if the weight of consumption utility is not negligible. Still, the magnitude of 
wage elasticities may be smaller compared than in a standard neoclassical model due to the existence of income targets.

Section 2 provides a description of the paua fishery, followed by the data and econometric method in section 3. The empirical analysis is presented in section 4 and section 5 details the model of reference-dependent preferences. Finally we conclude in section 6. 


\section{Paua (abalone) fishery}

In New Zealand abalone are commonly known by their indigenous Maori name, paua. Paua occupy rocky intertidal and sub tidal habitats to a depth of 10-15 meters and are gathered by hand while free diving in shallow waters, usually not more than 6 metres off the coastline (Ministry of Fisheries 2006). They are known to form large aggregations on reefs, possibly to enhance fertilization, shelter or feeding. Divers tend to move amongst patches targeting large aggregations to maximise rent (McShane 1995). Movement of adult paua occurs over a very small spatial scale so that they are considered sedentary, but patches are loosely connected with each other so that local populations are aggregated into metapopulations. The fishing industry contributes NZ\$1.7 billion $^{3}$ per annum to the gross domestic product of New Zealand with paua among its top 10 seafood export species. New Zealand is a key player in the international abalone market, where nearly all of the paua is sold processed (canned) worth approximately NZ\$50 million in 2006 (SeaFIC 2006).

On 1 October 1986 paua was among the first species to be adopted into New Zealand's rights-based management response to dwindling inshore stocks, the individual transferable quota (ITQ) system. Each year the government sets an overall total allowable commercial catch (TACC) for a specific species in a specific area, and the ITQs are well defined rights to harvest a percentage share of this TACC. Owners can buy (sell) parts of their ITQ holdings in order to increase (reduce) their landings. The amount an owner is allowed to catch within the next fishing year is known as an annual catch entitlement (ACE). To enhance flexibility of the system, ITQ owners may lease part of their ACE to other divers. The result is that anyone may enter the industry by buying ITQs or leasing ACE at any time but a maximum

\footnotetext{
${ }^{3}$ NZ\$1 = US\$0.74, November, 2010.
} 
limit is enforced to inhibit monopolistic behaviour. ${ }^{4}$ The underlying theory is that owners of ITQs may trade them freely in a competitive market generating price signals, which provide important information on the profitability and sustainability of the fishery. ${ }^{5}$

In New Zealand, the TACC for paua applies to eight distinct quota management areas (QMAs) covering the whole of the country's coastline, i.e. each QMA has its own TACC. Once the TACC for a given QMA and a given year is determined, the tonnage equivalent of each ITQ percentage share is calculated and transferred to the ITQ owner on the first day of the fishing year. There is a minimum legal size for paua and divers are banned from using Scuba, but may use snorkelling gear. Figure 1 shows the boundaries of the three QMAs of interest to our study in the southern tip of New Zealand: PAU 5A (Fiordland), PAU 5B (Stewart Island) and PAU 5D (Southland/Otago). Each QMA is further divided into fine-scale statistical areas for reporting purposes (not shown in figure 1).

\section{[Insert figure 1]}

Diving conditions in the southern tip of New Zealand are fairly homogeneous across the three areas shown in figure 1 and the average price of paua ACE traded has converged across the three QMAs to NZ\$ 28 per kg in 2006. Becoming a paua diver is a fairly accessible profession for any physically healthy individual in New Zealand. The costs associated with securing ACE are high but participation costs in

\footnotetext{
${ }^{4}$ For example, under the Fisheries Amendment Act 1986, no one can own or lease more than $20 \%$ of paua ITQs in a single QMA.

${ }^{5}$ Newell et al. (2005) find support for a competitive market for economically important fish stocks in New Zealand and conclude its ITQ system is a potentially effective instrument for efficient fisheries management.
} 
the fishery are relatively low (Ministry of Fisheries 2007). This has driven a change in recent years where few ITQ holders fish their own ACE but use contract divers instead.

\section{Data and econometric method}

\subsection{Data}

The empirical analysis uses data collected by the Ministry of Fisheries in New Zealand. Paua divers have to fill in a Paua Catch Effort and Landing Return after each “diving trip”, which typically refers to one day of diving activity (from here on referred to as dive occasion). The three datasets for PAU 5A, 5B and 5D stretch from 1 October 2001 to 30 September 2006, which cover five full fishing years for paua. Data go back to 1986-87, but reporting requirements were revised and made mandatory for each individual diver after each dive occasion from 1 October 2001 onwards ${ }^{6}$.

Each of the three datasets contain uniquely computer generated keys to indicate the dive occasion (event key), the individual ACE holder (ACE holder key), the individual vessel (vessel key), the individual diver (diver key) and information on the date of the dive occasion, the statistical area, fishing duration (hours dived), the amount of total catch per dive occasion $(\mathrm{kg})$ and codes identifying the diving conditions at the time of fishing. ${ }^{7}$ An additional dataset provides annual ACE

\footnotetext{
${ }^{6}$ All data are confidential.

${ }^{7} \mathrm{E}=$ excellent, very good visibility, lot less swell than usual for this area and time of year; $\mathrm{G}=$ good, better than average, but not as good as excellent; $\mathrm{A}$ = average visibility and the swell was average for this area and time of the year; $\mathrm{P}=$ poor conditions, better than very poor, but not as good as average;
} 
entitlements of all active ACE holders in the relevant QMAs, which can be directly linked to the ACE holder keys. Note, given the nature of QMA-specific ACE allocations and distances, divers do not typically dive across QMAs within a given fishing year.

The occurrence of paua in shallow, inshore areas has engendered fairly homogenous boat sizes, less than $15 \mathrm{~m}$ long, with little capital being tied up in vessels (Ministry of Fisheries 2007). Preferably, ports of landing should be known to calculate fuel costs and time spent steaming along the coast to the individual statistical areas. The datasets provide no identifiable points of landing and we have no means of discerning travelling costs to the individual diving locations. However, travelling distances are relatively short compared to most other fisheries, typically divers leave in the morning and return to port of landing the same day.

\subsection{Econometric method}

The main goal of the empirical analysis is to explore the relationship between hours that divers choose to work each day and the average daily wage. Wage elasticity is defined as $\varepsilon=\frac{d h_{t}}{d w_{t}} \frac{w_{t}}{h_{t}}$

where $w_{t}$ represents the wage rate and $h_{t}$ the hours of labour supply provided. Repeated use of the chain rule reveals that

$$
\varepsilon=\frac{\partial \ln h_{t}}{\partial \ln w_{t}}
$$

$\mathrm{V}=$ very poor visibility for this area and time of year, and there was a lot more swell than usual for this area and time of year; UNREPORTED = diver did not supply the information. 
Empirical studies use simple regressions of log hours on log wages, which we replicate but further analysis shows the significance of including both log wage squared and log wage cubed terms.

$\operatorname{lnh} h_{t}=\alpha+\beta_{1} \ln w_{t}+\beta_{2} \ln w_{t}^{2}+\beta_{3} \ln w_{t}^{3}+\beta_{i} X_{i}+e$

where $\beta_{i} X_{i}$ represents a set of dummy variables included to control for weather and seasonal effects, and lagged terms of log wage and log hours. Given equations (1) and (2) it follows that the wage elasticity is not a single value evaluated at the sample mean but varies over the interval of observed wages according to

$\varepsilon=\beta_{1}+\left(2 \times \beta_{2} \times \ln w_{t}\right)+\left(3 \times \beta_{3} \times \ln w_{t}^{2}\right)$

\section{Empirical analysis}

\subsection{Descriptive statistics}

In table 1 we report summary statistics for divers across the three areas for the whole time period 2001-02 to 2005-06. Pay incentives for divers are confidential and vary among ACE holders and from area to area, but the standard arrangement is that the harvest crew receive a stable, flat price per kilogram after each catch, which for 2009 was in the range NZ\$ 6-10 per $\mathrm{kg}$. It is common that the boat owner is another person, who sets the deal with the ACE holder, and then splits the proceeds fifty-fifty with the diver. ${ }^{8}$ Hence, divers earned on average NZ\$ 3.7 per kg (in constant 2006 NZ dollars) during each year of the periods studied. Based on these assumptions, we

\footnotetext{
${ }^{8}$ Personal communication with Jeremy Cooper, CEO Paua Industry Council Ltd.
} 
report catch per trip in kg and average wage per hour in \$NZ. Divers spent between 4 and 5 hours on average in the water, made NZ\$105-167 per hour and earned gross revenues of NZ\$248-836 per trip (latter value not shown in table 1). The average annual diver income (gross revenue times the number of dive occasions per diver p.a.) is $\mathrm{NZ} \$ 4,464-12,775$, which is substantially below the average annual pre-tax income of NZ\$29,991 in agriculture, forestry and fishing and NZ\$38,940 in manufacturing (Statistics New Zealand, 2009). Our data confirm the general notion that divers have additional income from other seasonal employment such as meat works, orchard work and other fishing/diving work. Given our figures, paua diving is likely to contribute roughly $30 \%$ of their annual income.

\section{[Insert table 1]}

Table 2 shows that the composition of ACE holders and divers within the three datasets is fairly homogeneous. The first and second row show that a total of 30-32 ACE holders are active between the fishing years 2001-02 and 2005-06 employing a total of 258-442 divers, confirming that a vast majority of divers are not ACE holders. On average, 88-140 divers are actively working in any given year. Each diver works on average for 1.2-1.3 ACE holders while ACE holders employ 9.9-17.4 divers on average.

\section{[Insert table 2]}

The last three rows of table 2 indicate the entry and exit pattern in each QMA. ACE holders are active in nearly all of the fishing years (3.3-3.7 years), while divers are only active for an average of 1.6-1.7 years. We find that about $70 \%$ of all divers in each data set exit the QMA within a year, indicating low barriers of entry and exit. When eliminating all those who exit the QMA after one fishing year, the remaining number of divers is reduced to 112, 77 and 113 in PAU 5A, 5B and 5D respectively. 
The last row in table 2 shows an increase in average number of active fishing years to 3.1-3.4. These experienced divers constitute roughly 30\% in each sample but carry out more than $80 \%$ of the dives.

The first row in table 3 shows that on average, each diver completes all of his or her dive occasions within 2.2-2.4 months within the fishing year (medians shown in parenthesis), i.e. divers work on average for approximately 2 out of 12 months. However, for experienced divers (referred to as the 'experienced diver subset' in table 3), the average annual number of diving months is 3.8-4.4. The remaining rows in table 3 indicate that divers complete on average 2.3-3.0 (2) dive occasions within one month, with an average of 1.6-2.5 (0) days elapsing between these occasions (the values for the experienced diver subset are very similar).

Table 3 establishes the temporal work pattern of a typical core (experienced) diver who works approximately 3 to 4 months within a fishing year and undertakes 2 to 4 dive occasions with up to three days' break within each of those months. No clear monthly work pattern emerges from the data. The mean (median) number of elapsed months of diving activity within a fishing year is approximately 3 (2) months across the three QMAs (not shown in table 3). Thus we observe a pattern of short term bursts of diving activity spread over the fishing year. This finding is consistent across the three datasets. At the maximum, divers carry out up to 35-71 days of diving per annum (see table 1).

[Insert table 3]

Figures 2, 3 and 4 represent histograms of catch per unit of effort (CPUE) in intervals of $10 \mathrm{~kg}$ (measured as catch per hour), the hours spent diving in intervals of one hour and the number of dive occasions for each of the 6 weather codes (see 
footnote 6). The vertical axes represent the percentage frequency out of total observations to facilitate comparison between QMAs. Clearly, divers experience substantial variations in CPUE and work hours across the three QMAs. Figure 4 shows that most dive occasions occur during average weather conditions.

[Insert figures 2, 3 and 4]

Divers do not always go fishing by themselves. The datasets allow us to identify the occasions when divers share a vessel by comparing vessel keys for each diver on a given date. Table 4 shows that each vessel carries 2-3 divers on average on each dive occasion, however, the mean absolute deviation from the average catch and hours dived for each vessel on each dive occasion is relatively low. This implies coordinated behaviour across divers on a vessel in terms of the number of hours dived and the amount of catch.

[Insert table 4]

\subsection{Wage Elasticity}

Starting with estimation of equation (2) without the higher polynomial order of log wages, we obtain weak and mixed results regarding the wage elasticity in PAU 5A (0.2), PAU 5B (-0.1) and PAU 5D (0.05). These regressions were run including dummies representing weather conditions, the day of the week, the month of the year, and yearly dummies (not shown). In table 5, we report the regression results for the three QMAs for the model according to equation (2). Regressions have also been run to account for clustered standard errors within divers, robust estimators, diver fixed effects, vessel fixed effects, weather fixed effects and area fixed effects with no improvements on model fits or qualitative changes of the coefficients (not shown). 
We find a simple ordinary least square regression to present the best fit of model as shown in table 5 .

[Insert table 5]

The coefficients on log wage, log wage squared and log wage cubed are highly significant for PAU 5A and 5B, while the best fit is achieved including only log wage and log wage squared for $5 \mathrm{D}^{9}$. A variable indicating the number of elapsed days since the last dive occasion (by diver and by month) has been omitted to avoid losing out on a substantial number of observations and a reduced model fit. Weather, day of the week, month of the year and yearly dummies are significant to various degree and do not reduce the fit of the model or alter the qualitative and quantitative values of log wage, log wage ${ }^{\wedge}$ and $\log$ wage ${ }^{\wedge} 3$ significantly when omitted. The adjusted $\mathrm{R}^{2}$ values range from 0.117 to 0.173 .

In figures 5, 6 and 7 we show the estimated wage elasticities, using equation (3), where the wage levels are calculated by the product of the CPUE and the average annual prices paid to a diver without boat and ACE (in NZ\$ 2006). For approximately $97 \%$ of the observations a clear pattern emerges. At low wage levels, divers work short hours in line with neoclassical predictions but at high wages divers work equally short hours.

For PAU 5A, the wage elasticity is positive with a maximum of $0.56,0.10$ in PAU 5B and 0.34 in PAU 5D. As the wage rate increases, the wage elasticity progressively declines until it turns negative and continues to about -1 for PAU 5A

\footnotetext{
${ }^{9}$ Including log wage cubed in the estimations for PAU 5D renders all wage terms insignificant and reduces the fit of the model.
} 
and 5B (the number of observations below -1 are 15 and 9, respectively) and to about -0.5 for PAU 5D.

[Insert figures 5, 6 and 7]

There is an increasing interest in the potential differences in decision making comparing individuals and teams. Some results indicate such differences, e.g. that teams act more strategically (Cooper and Kagel, 2005) and that teams are less myopic loss averse than individuals (Sutter, 2007). We tested the robustness of the estimated wage elasticities for a split sample of vessels carrying more than 1 diver vs. divers fishing by themselves ${ }^{10}$. Table 6 shows the regression results across the three QMAs for the split samples. The dependent variable for the first sample ("vessels with $>1$ divers") is the average of hours spent diving across the number of divers sharing the same vessel on the same dive occasion. Calculated in the same way, average vessel wages represent the explanatory variables, while diver-specific hours and wages are used for the second sample ("vessels with 1 diver"). Table 6 reports the regression results. In some instances the cubed term is insignificant and is omitted, however, the derived elasticities (not shown here) follow the same shape in more or less the same range of magnitude as shown in figures 5, 6 and 7 (although the effect of non-constant elasticities appears to be slightly stronger in magnitude for divers sharing a vessel). The correlation coefficients between average vessel wages and diver-specific wages of 0.88, 0.92 and 0.73 for PAU 5A, 5B and 5D (not shown), respectively, support the impression that divers are a fairly homogenous group of agents, i.e. there seems to be no marked difference in the behaviour of divers sharing a vessel and divers operating alone.

\footnotetext{
${ }^{10}$ Wage elasticities were also estimated for diver teams of 2, 3 or more divers (not shown in table 6) but no qualitative differences can be observed.
} 


\section{[Insert table 6]}

Could capacity constraints in terms of the maximum load of paua that fits on a small commercial vessel drive the observed negative labour supply at a high wage rate? We calculate the total vessel catch on a given dive occasion (i.e. the sum of catch for all divers sharing the same vessel) and then identify the maximum vessel specific catch given all observations. This provides us with an indication of vessel specific capacity. In a last step we calculate the total vessel catch on a given dive occasion as a percentage of the vessel capacity i.e. the capacity utilization rate ${ }^{11}$. At the $50^{\text {th }}$ percentile the capacity utilization rate is less or equal to $25-33 \%$ (with 1,053 observations for PAU 5A, 1,916 for 5B and 1,892 for 5D), at the $75^{\text {th }}$ percentile it is less or equal to $42-50 \%$, at the $90^{\text {th }}$ percentile $64-73 \%$ and at the $95^{\text {th }}$ percentile 80 94\%. The percentile values show that the absolute maximum vessel capacity is rarely reached, i.e. there seem to be no obvious capacity constraints that drive our estimation results. However, it should be noted that capacity utilization rates as high as $70-80 \%$ may imply increased security risks of operation.

\subsection{Analysis}

In order for our interpretation of labour supply responses to transitory wage changes in the previous section to hold, wages have to be constant within a day, i.e. our model is based on the assumption that average earnings are equal to marginal

\footnotetext{
${ }^{11}$ More sophisticated methods to estimate capacity in fisheries, such as stochastic production frontier methods and nonparametric methods (e.g. data envelopment analysis), exist but are beyond the scope of this paper.
} 
earnings. Given the reporting format it is not possible to discern correlation coefficients of wages between hours dived within a given day. The size and distribution of paua clusters has important implications on the behaviour of divers. If paua occur in large, fairly unevenly distributed patches divers who strike a 'lucky' patch may harvest this patch at a faster rate during their diving activity to the extent that marginal wages are not representative of average wages.

Two fishery independent surveys show that the mean percentage of paua occurring in aggregations of greater than 20 in sites sampled in PAU 5B and 5D is somewhere around 5\%, with a declining trend (Ministry of Fisheries 2000; Ministry of Fisheries 2004). This indicates that paua are generally found in small clusters of less than 20. The surveys also show that a mean number of 40-120 paua are found per 10 minute diver search, i.e. the surveys suggest that paua patches are small and fairly frequently encountered on rocky habitat. Divers initially locate a suitable diving location focusing on chains of coastal rocks, anchor their boat and swim around these rocks to find paua patches. The size and frequency of paua patches suggests homogeneous working conditions once suitable habitat is located, i.e. average wages may approximate marginal wages. Note, our data on fishing duration (hours dived) relate to the time spent in the water.

Another concern relates to the fatigue effect, i.e. does physical exhaustion constrain the physical amount divers are able to harvest and thus influence the number of hours worked? Focusing on wages above the $90^{\text {th }}$ percentile to represent 'very high wage days' in each of the three areas (leaving us with 315 observations for PAU 5A, 323 observations for 5B and 491 observations for 5D), we find that while three quarter of the observations ( $75^{\text {th }}$ percentile) are equal or less than 6-7 hours, a small percentage of divers do go on to dive the maximum number of 8-10 
hours despite earning a very high wage. While there may be confounding factors in terms of weather, water temperature, physical ability and other unobserved determinants that influence the level of physical exhaustion of any particular diver, it provides indirect support that it is possible for divers to harvest large quantity of paua and work long hours.

Our data do not allow for a direct test of fatigue, however, reported total amount of catch and total number of hours dived on any given dive occasion provide a basic production function. Operating on the premise that a significant fatigue effect exists and divers exhibit less productive harvesting behaviour as the number of hours spent in the water increases, we would expect catch to increase at a decreasing rate, i.e. a decreasing marginal product. When estimating the production function as a simple power function $\left(\right.$ catch $\left._{t}=a \times h_{t}^{b} \times u\right)$ and transforming it into a log function $\left(\operatorname{lncatch}_{t}=\ln a+b \times \ln h_{t}+\ln u\right)$ the size of the estimated coefficient $b$ provides indication as to whether the marginal product is increasing $(b>1)$, decreasing $(b<1)$ or constant $(b=1)$. We find the estimated coefficients to be very close to 1 ( $b=1.2$ for PAU 5A, $b=0.91$ for $5 \mathrm{~B}$ and $b=1.05$ for $5 \mathrm{D}$ ), i.e. the marginal product is more or less constant. The analysis lends further support to our assumption that no strong fatigue effect exists.

Furthermore, we investigate correlation coefficients of log hours dived on successive dive occasion (i.e. the correlation coefficients between today's (t) log of hours and the next day's ( $t+1)$ log of hours, as well as any other number of days ahead for divers returning to the same statistical area as well as any other area within the same QMA). Table 7 shows that correlation between the log of hours is always significant and positive, but of a substantially lower magnitude. The general impression is that a long day is followed by a long day, and corresponding for a short 
day. Hence, divers are not exhausted (recovered) from a long (short) day leading to an impact of the length of the subsequent day, i.e. there is no obvious exhaustion (recovery) effect in the short term.

\section{[Insert table 7]}

Informal discussions with divers stress underwater visibility/weather as the most important determinant for creating favourable harvesting conditions, i.e. weather codes are a strong determinant of daily wage rates. To rule out the possibility that changes in weather during the day may affect transitional wages, we give some closer consideration to the reported weather codes. We find that on any given day of reported dive occasions divers report the same weather code (i.e. the median of the number of different reported weather codes by QMA and by date is equal to 1) for the whole of the QMA in PAU 5A, 5B and 5D (apart from 5D where the median is 2), as well as for each statistical area (i.e. the median of reported weather codes by statistical area and by date is 1). This implies daily weather conditions are relatively stable across the whole of the QMA and across individual statistical areas, ruling out any area-dependent effects that may affect wages within a QMA. Note, however, due to the small fraction of days dived within a fishing year, a median of only 3-4 divers are active on any of the days of reported dive occasions within the whole of the QMA and a median of 2-3 divers within any particular statistical area.

Further analysis has been conducted to examine the participation decision of divers by regressing the number of diving days by diver within a month on the average monthly wage, but the coefficients are very small (very close to zero) and the overall fit of the model low. Similarly, regressing the number of elapsed days between dive occasions by diver within a month on wage levels yields very low but significant coefficients. We conclude that wage levels seem to have little effect on 
the monthly participation decision and the timing of those dive occasions within the month. We also tested for measurement error and diver experience, but found very little effect on the qualitative results (see Appendix A1 and A2).

\section{Reference-dependent preferences}

The results of our empirical estimations challenge the neoclassical theory of intertemporal wage elasticities. KR's (2006) general theory of reference-dependent preferences, and their formulation of how cabdrivers' targets are determined in particular (see their Section V), may provide a plausible explanation for the observation that divers work short hours at low wages but equally short hours at high wages. KR (2006) pose the hypothesis that a cabdriver's utility depends on the level of consumption of goods and services and leisure as well as on a reference consumption level for goods and services and leisure. Previous attempts to model reference-dependence usually assumed only gain-loss utility, while this is a special case of the more general KR model (Crawford and Meng, 2010). Their analysis also differs from previous explanations of empirical results (such as by Camerer et al. 1997) in that drivers are assumed to have not only a daily target for income but also for the number of leisure or work hours (with work hours being a complement to leisure hours).

KR (2006) define an additively separable utility function composed of a consumption utility function, which represents the classical notion of outcome based utilities in that it is independent of the reference level, as well as of what they coin the reference-dependent 'gain-loss' utility, which captures the predictions of Kahneman and Tversky’s (1979) and Tversky and Kahneman’s (1991) Prospect Theory in that individuals are more sensitive to changes in their income below the reference point ('losses') than changes above it ('gains'). 
KR's (2006) theoretical contribution has brought forth a small number of studies investigating its empirical validity and implications (Abeler et al., in press; Crawford and Meng, 2010; Doran, 2009). Crawford and Meng (2010), in particular, propose a model of cabdrivers' labour supply decisions building on Farber $(2005,2008)$ and KR (2006). They estimate probit models of drivers' probability of stopping dependent on cumulative shift hours and income and find stopping probabilities to be more strongly influenced by the second target a driver reaches on a given day rather than the first, i.e. when earnings are high, hours (rather than income) has a significant impact on the stopping probability, while reaching the income target is the most important when earning are low.

The empirical findings in this study may be explained by KR's (2006) theory of reference-dependent preferences. Analogous to Crawford and Meng's (2010) figure 1 , the existence of both an income target and an hours target translates into an expected wage rate $w^{e}$ for each dive occasion. Divers experience exogenous variations in the wage rate determined by underwater visibility, i.e. good underwater visibility conditions and calm water conditions increase the success in finding consecutive patches of paua thereby increasing the wage rate. When diving conditions are adequate and the actual wage $w^{a}$ coincides with the expected wage rate $\left(w^{a}=w^{e}\right)$, divers are able to attain both their income and leisure target. This is indicated by the preference at the point of tangency at $a$ in Figure 8, where $c_{t}$ and $l_{t}$ represent the level of consumption of goods and services and of leisure hours, and $c_{r}$ and leisure $l_{r}$ the respective reference consumption level.

\section{[Insert figure 8]}

On a day where the actual wage rate is above the expected wage rate $\left(w^{a}>w^{e}\right)$ and starting from the maximum possible level of leisure $l_{\max }$ (i.e. zero work hours) a diver 
will attain his income target before reaching the leisure hours target. A diver may stop close to the first reached target or continue to work until reaching his second reached target at a point such as $b$. Note point $b$ lies slightly below the leisure hours target $l_{r}$ in what Crawford and Meng (2010) define as the income gain/leisure gain domain. Whether divers stop at their first reached or second reached target, the result remains the same: divers will choose to work less hours at an unanticipated high wage rate. This finding is in line with Crawford and Meng (2010) who predict a negative wage elasticity when the second reached target is the dominant influence on stopping.

The case of an actual wage below the expected wage rate $\left(w^{a}<w^{e}\right)$ implies divers reach their leisure hours target before their income target. Divers may stop at their first-reached target as indicated by point $e$ in the figure. If the neoclassical optimal income and hours (solely derived from the consumption utility) are lower than the targets, then stopping at $e$ may lead to a positive wage elasticity, albeit smaller in magnitude than in a standard neoclassical model. If divers have targets higher than the neoclassical optimal income and hours, they stop at their secondreached target, which increases the likelihood of negative wage elasticities (Crawford and Meng 2010).

Doran (2009) found that half of his sample had daily income reference points that increased for an expected permanent wage increase. We have daily data and do not attempt to estimate a full reference-dependent model like his or Crawford and Meng (2010). Still, could anything be said with respect to divers’ potential targets?

We calculate the annual average diver-specific wage to split our sample into 'low wage' and 'high wage' observations to distinguish between the influence of income and leisure hours targets (see figure 8). The results of a simple OLS 
regression with the log of hours as the dependent variable and the log of the pointexpectation hours and income targets as explanatory variables are shown in table 8. Following Crawford and Meng (2010) we proxy diver's income and hours targets by calculating monthly, diver-specific sample averages up to but not including the observation in question.

\section{[Insert table 8]}

The estimated coefficients in table 8 indicate that daily labour supply decisions across PAU 5A, 5B and 5D are strongly influenced by the leisure hours target, but not by the income target, when wages are lower than expected, leading to a positive wage elasticity. The results are less clear cut for unexpectedly high wages. Both the income and the leisure hours target are significant in PAU 5A, with the latter being higher in magnitude, but only the hours target is significant for PAU 5B and 5D. The results in table 8 provide some support to the hypothesis that our divers care about their first-reached target for unexpectedly low wage days as a major influence on length of the working day, while on unexpected high wage days mostly the second reached target matters, i.e. the leisure hours target

\section{Conclusion}

Paua divers in southern New Zealand constitute a group of workers that are free to set their working hours on a daily basis and are exposed to large temporary variations in wage levels. According to neo-classical theory they should work long hours a day when wages are high and short hours a day when wages are low, but our results reject this prediction. In fact, divers have negative wage elasticities for high wage days, and zero wage elasticities for medium wage days. We explore factors that may 
distort behaviour, but find little evidence. The size and frequency of paua patches indicate that average wages approximate marginal wages and further data analysis argues against a substantial fatigue effect that could lead to negative elasticities for high wages days. Weather is the most prominent determinant for favourable catch conditions and is found to be stable over areas supporting the notion that wages are stable within a day. Capacity limitations could be another factor influencing work hours, but we find little support for such constraints to influence working hours. In addition, we also looked at individual decision making versus group decision making as some divers operate alone while others in group. Our results do not detect any significant differences in behaviour between these two subgroups in our sample.

To explain the behaviour of divers we use the reference-dependent theory developed by KR (2006), which assumes that workers have rational expectations and form endogenous income and hours targets. Our results with non-linear wage elasticities do not fit into the neo-classical theory, but fit with the insight from KR's theory and the analysis by Crawford and Meng (2010). Crawford and Meng (2010) found that behaviour was more strongly influenced by the second-reached target on a given day irrespective whether drivers experienced unanticipated low or high wages. Our results indicate that the first-reached target is the most influential determinant of working hours on low wage days, while it on high wage days it is mostly the second reached target, i.e., divers appear to be guided by their leisure hours target primarily. Both outcomes are possible within KR's theory and we note that the result depends on where the targets stand relative to the optimal solution from the consumption utility alone. Our results add to the small but growing set of studies which indicate that reference-dependent models of KR's type will lead to a more comprehensive understanding of labour supply behaviour. 


\section{References}

Abeler, J., Falk, A., Goette, L., Huffman, D. (forthcoming). Reference Points and effort provision. American Economic Review.

Camerer, C., Babcock, L., Loewenstein, G., Thaler, R., (1997). Labour supply of New York City cabdrivers: one day at a time. Quarterly Journal of Economics, 112(2), 407-441.

Card, D. (1994). “Intertemporal Labor Supply: An Assessment.” In Advances in Econometrics: Sixth World Congress of the Econometric Society Vol. II, ed. Christopher A. Sims, 49- 78. Cambridge: Cambridge University Press.

Cooper, D.J., Kagel, J.H. (2005). Are two heads better than one? Team versus individual play signalling games. American Economic Review, 95(3), 477-509.

Crawford, V.P., Meng, J. (forthcoming). New York City cabdrivers’ labour supply revisited: reference-dependence preferences with rational-expectations targets for hours and income. American Economic Review.

Dickens, W.T., Lundberg, S.J. (1993). Hours restrictions and labor supply. International Economic Review, 34(1), 169-192.

Doran, K.B. (2009). Reference Points, Expectations, and Heterogeneous Daily Labor Supply. Manuscript, University of Notre Dame.

Farber, H.S. (2005). Is tomorrow another day? The labor supply of New York City cabdrivers. Journal of Political Economy, 113(1), 46-82.

Farber, H.S. (2008). Reference-dependent preferences and labor supply: the case of New York City taxi drivers. American Economic Review, 98(3), 1069-1082. 
Fehr, E., Goette, L. (2007). Do workers work more if wages are high? Evidence from a randomized field experiment. American Economic Review, 97(1), 298-317.

Goette, L., Huffman, D. and E. Fehr. (2004). Loss Aversion and Labor Supply. Journal of the European Economic Association 2(2/3): 216-228.

Kahneman, D., Tversky, A. (1979). Prospect theory: an analysis of decision under risk. Econometrica, 47(2), 263-291.

Kőszegi, B., Rabin, M. (2006). A model of reference-dependent preferences. Quarterly Journal of Economics, 121(4), 1133-1166.

Lucas, R.E., Rapping, L.A. (1969). Real wages, employment, and inflation. Journal of Political Economy, 77(5), 721-754.

McShane, P.E. (1995). Estimating the abundance of abalone: the importance of patch size. New Zealand Journal of Marine and Freshwater Research, 46, 657-662.

Ministry of Fisheries. (2000). Fishery independent surveys of paua (Haliotis iris) in PAU 5B amd 5D. Andrew, N.L., Naylor, J.R., Gerring, P. And Norman, P.R., New Zealand Fisheries Assessment Report 2000/3.

Ministry of Fisheries, (2004). Fishery-independent surveys of the relative abundance and size-structure of paua (Haliotis iris) in PAU 5D. Naylor, J.R. and Kim, S.W., New Zealand Fisheries Assessment Report 2004/48.

Ministry of Fisheries, (2006). Report from the Fisheries Assessment Plenary, May 2006: stock assessments and yield estimates, Wellington, New Zealand.

Ministry of Fisheries, (2008). Report from the Fisheries Assessment Plenary, May 2008: stock assessments and yield estimates, Wellington, New Zealand.

Ministry of Fisheries. Paua Fisheries Plan, Dunedin, New Zealand. 
Oettinger, G.S., (1999). An empirical analysis of the daily labor supply of stadium vendors. Journal of Political Economy, 107(2), 360-392.

SEAFIC, (2006). Exports of Seafood Produce for 12 Months ending December 2006, Seafood Industry Council (SeaFIC), New Zealand, www.seafood.co.nz, accessed July 2007.

Statistics New Zealand, (2009). Earnings from wage and salary jobs by industry can be downloaded from www.stats.govt.nz

Sutter, M., (2007). Are teams prone to myopic loss aversion? An experimental study on individual versus team investment behaviour. Economic Letters, 97(2), 128132.

Tversky, A., Kahneman, D. (1991). Loss aversion in riskless choice: a referencedependent model. Quarterly Journal of Economics, 106(4), 1039-1061. 


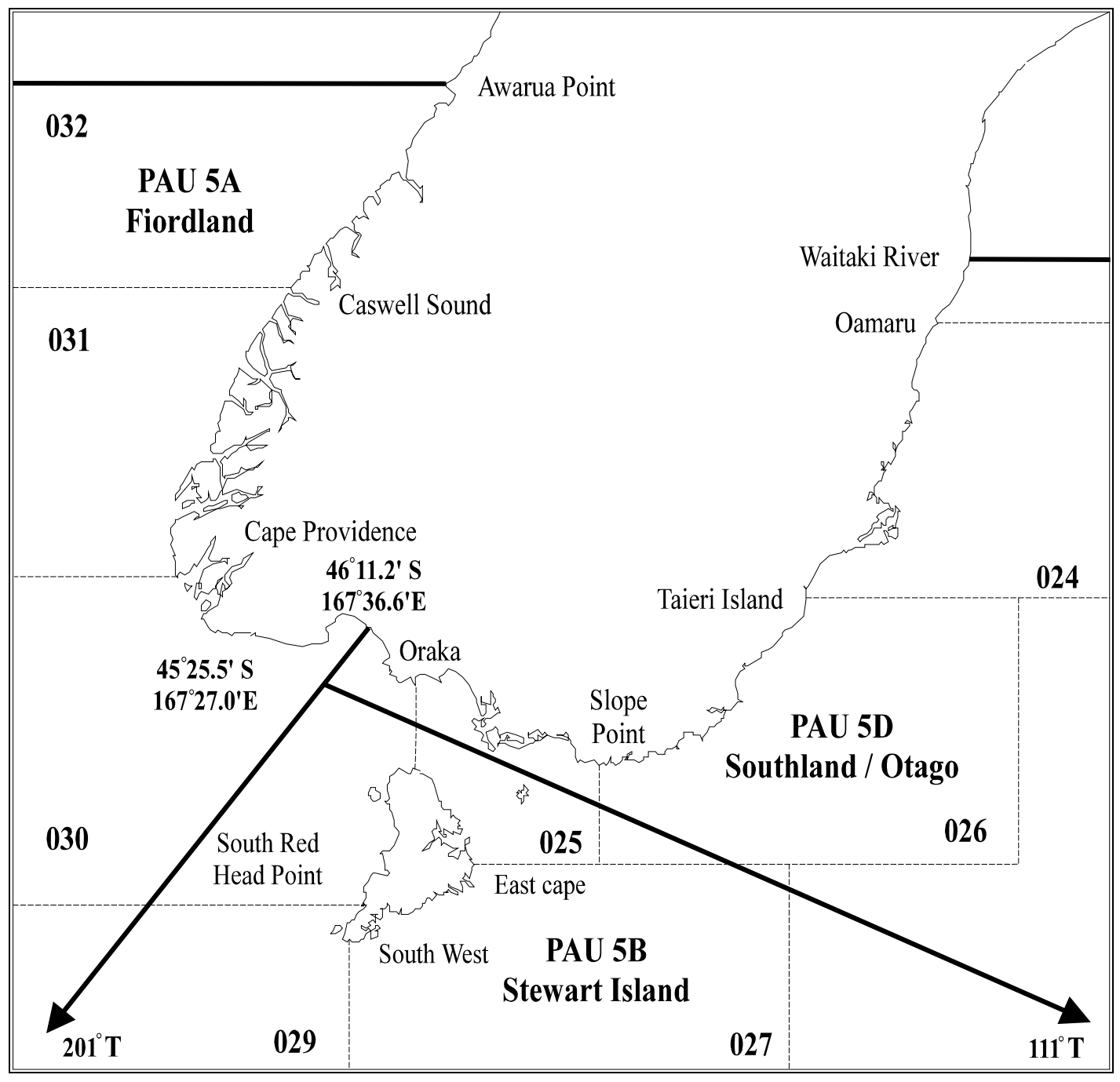

Figure 1. Boundaries of PAU 5A, 5B and 5D in the southern tip of New Zealand. 


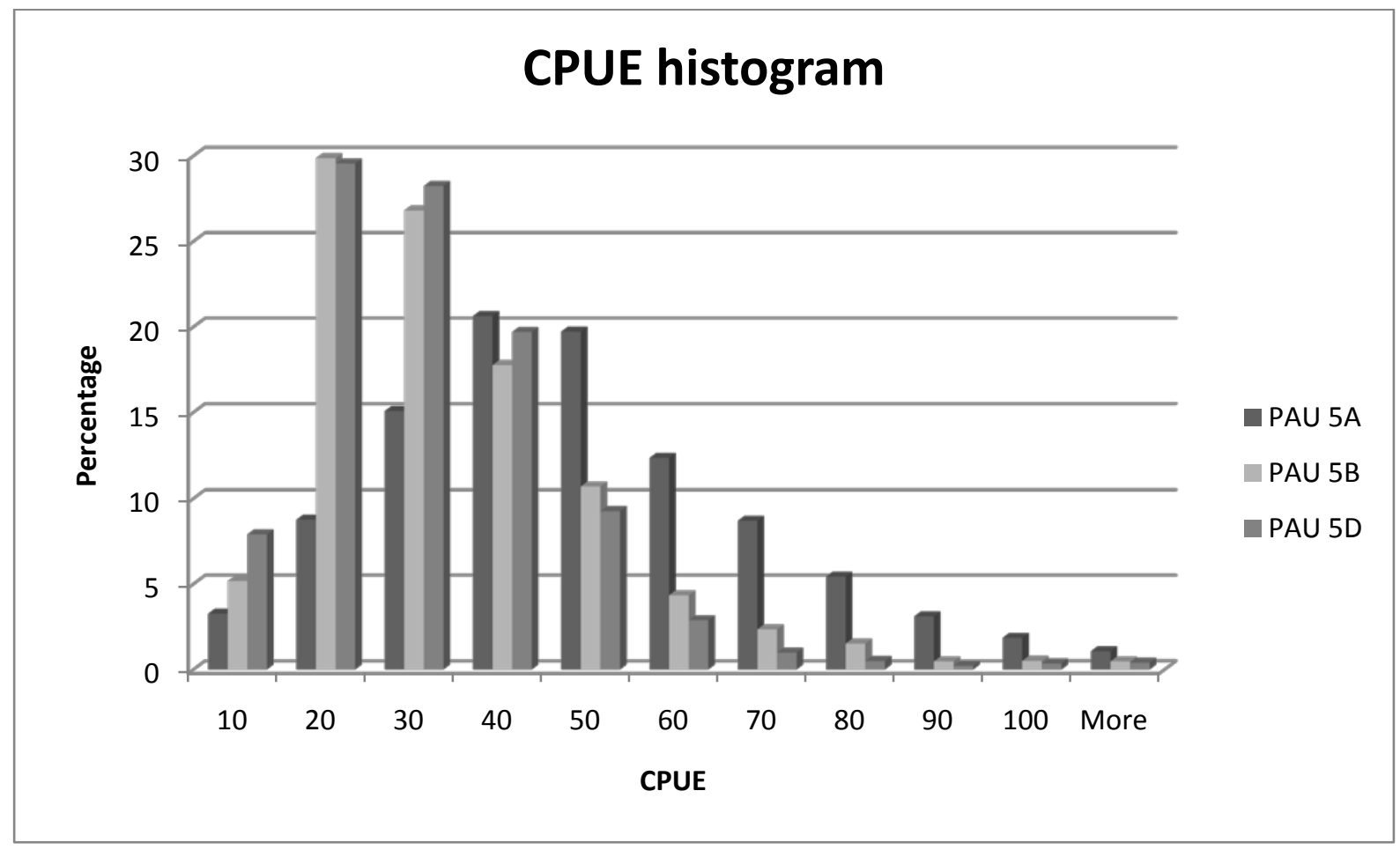

Figure 2. Catch per unit of effort (CPUE) histogram (measured in kg of catch per hour).

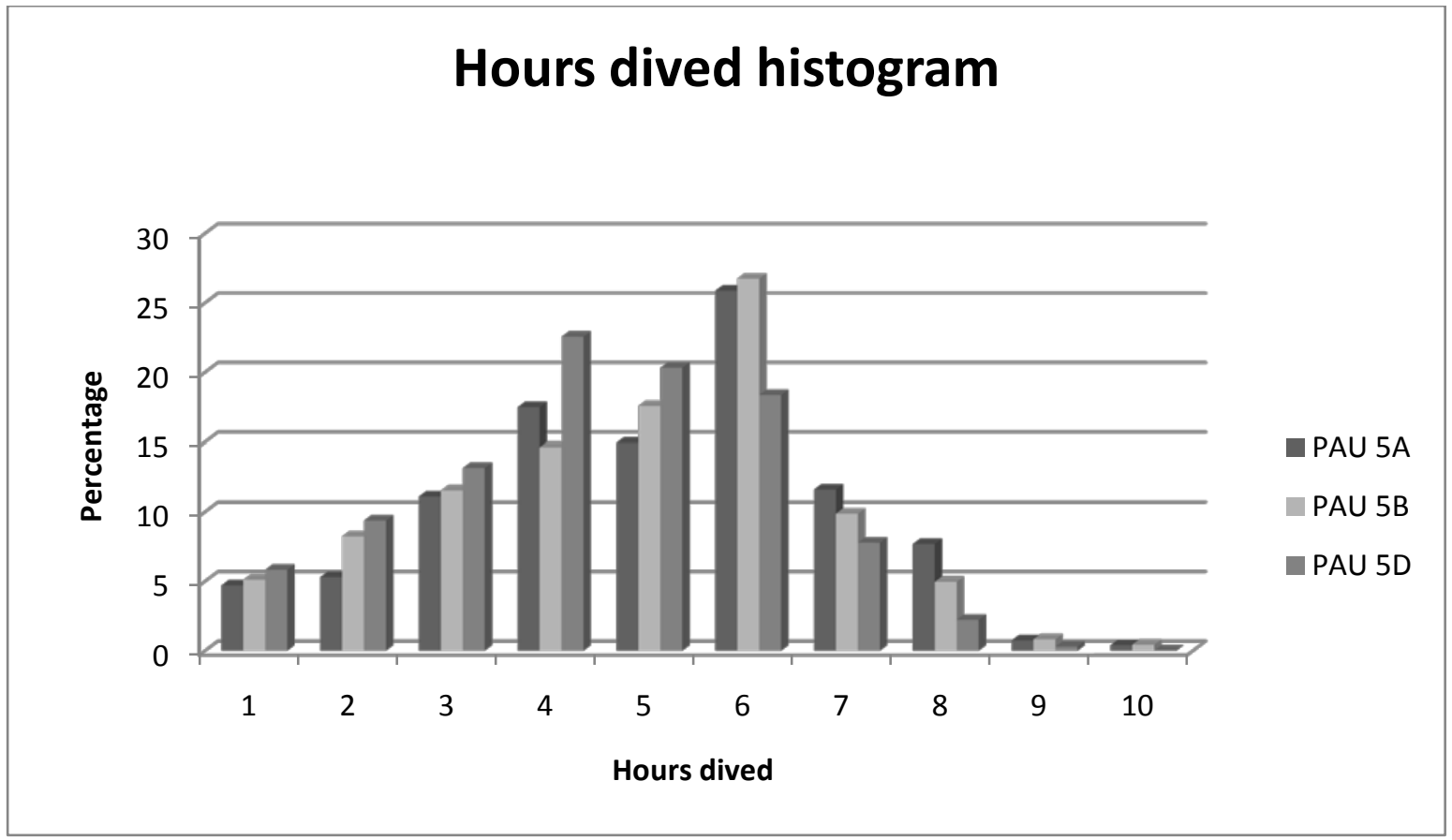

Figure 3. Hours dived histogram. 


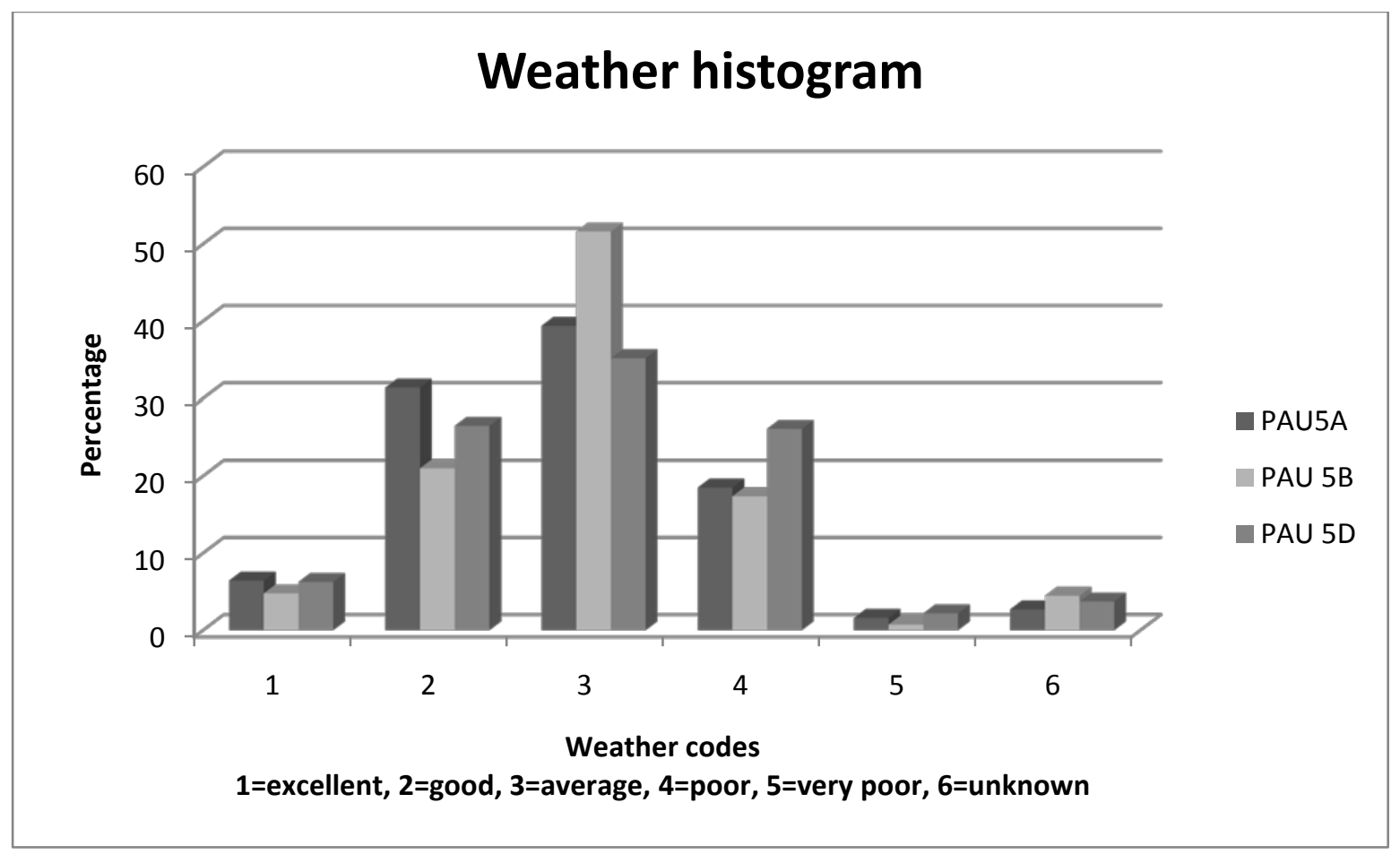

Figure 4. Weather histogram.

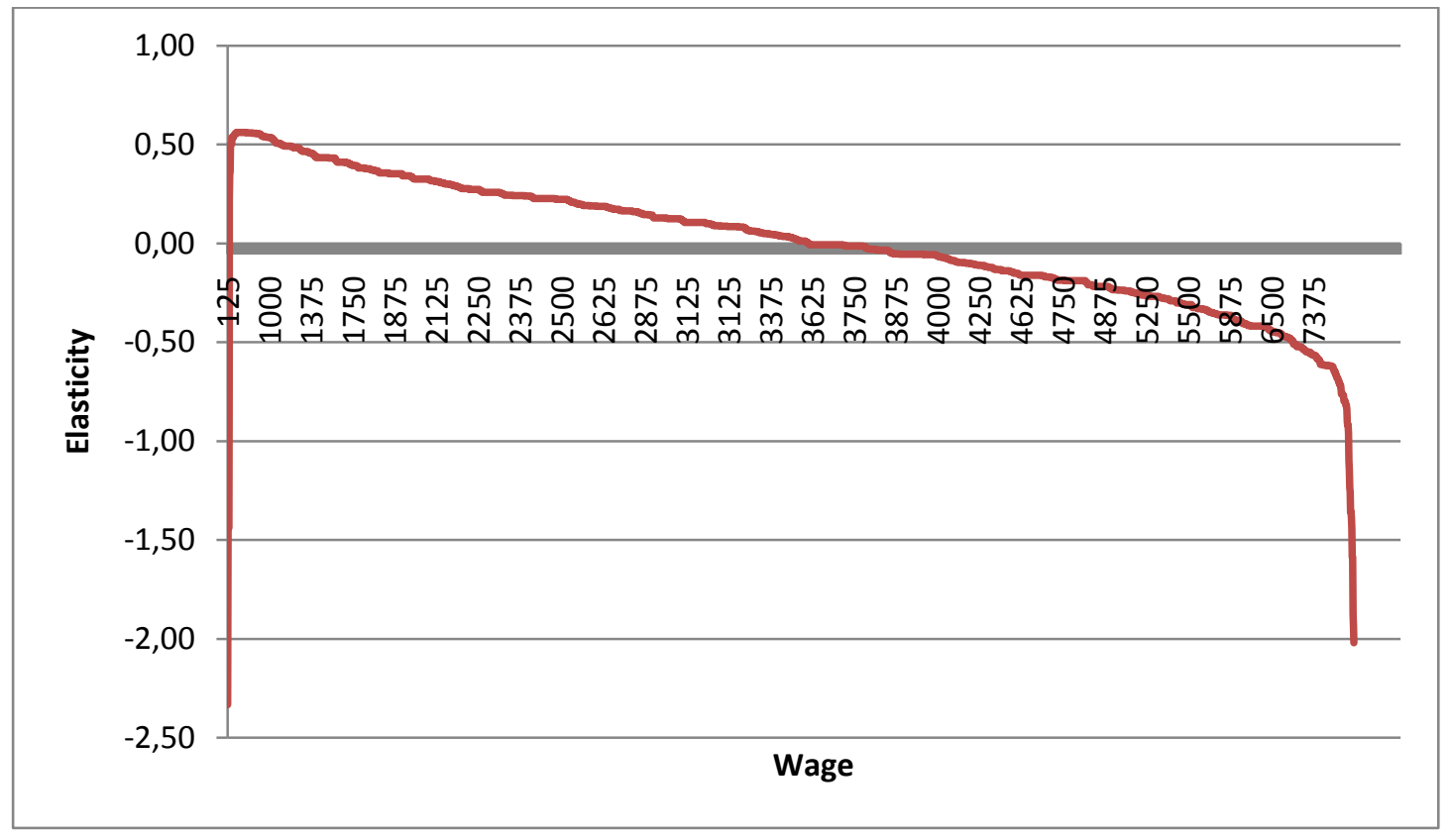

Figure 5. Wage elasticity in PAU 5A. 


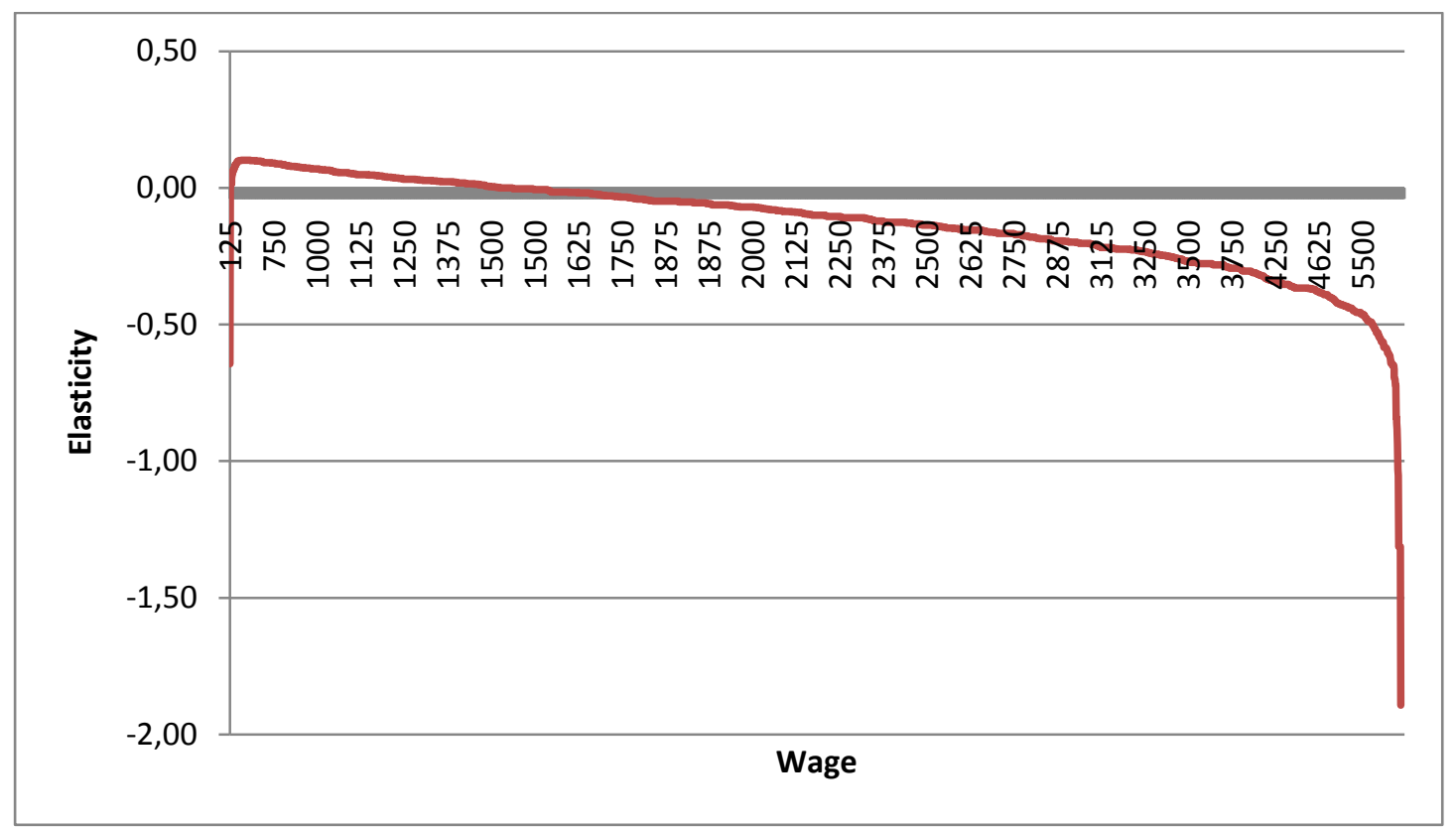

Figure 6. Wage elasticity in PAU 5B.

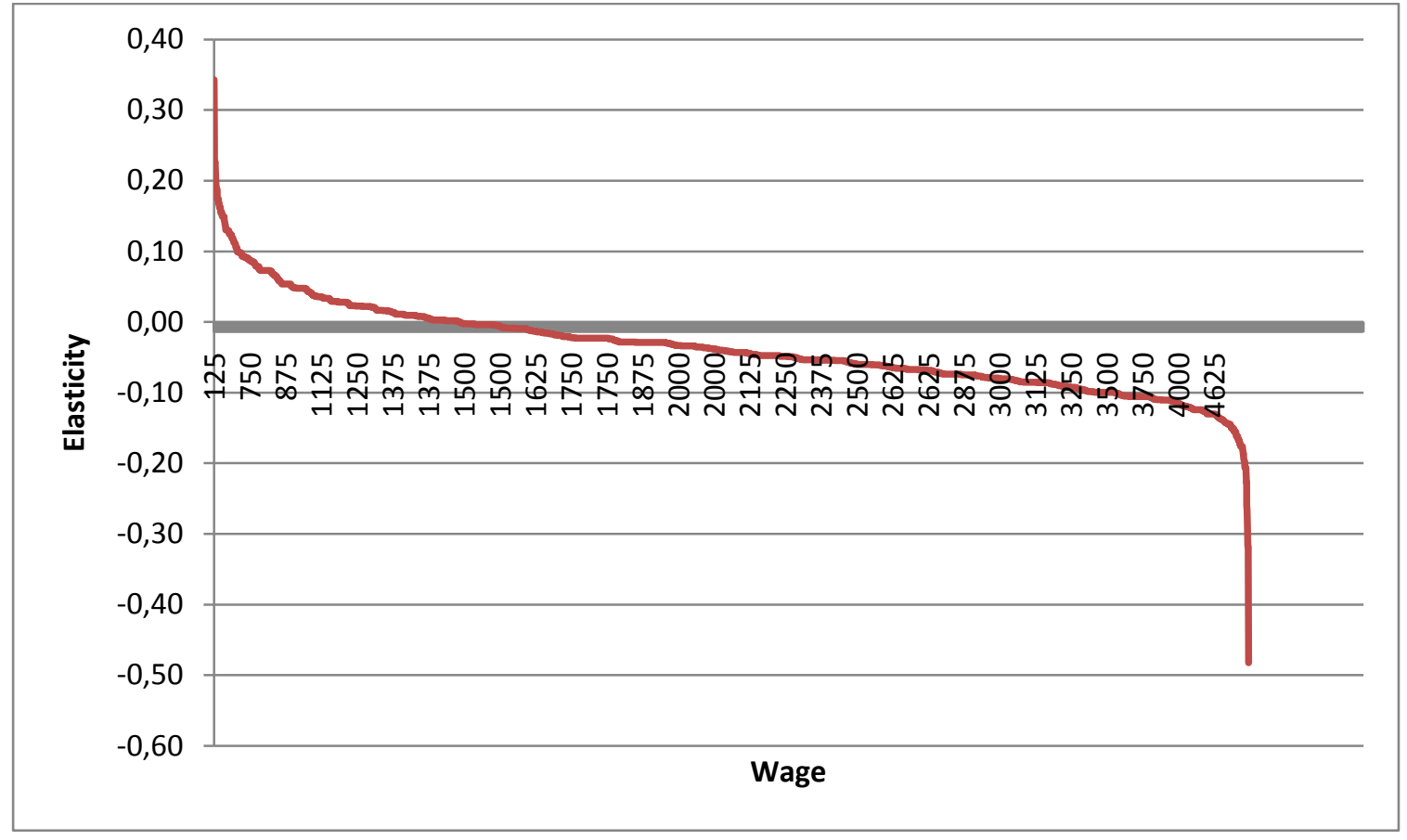

Figure 7. Wage elasticity in PAU 5D. 


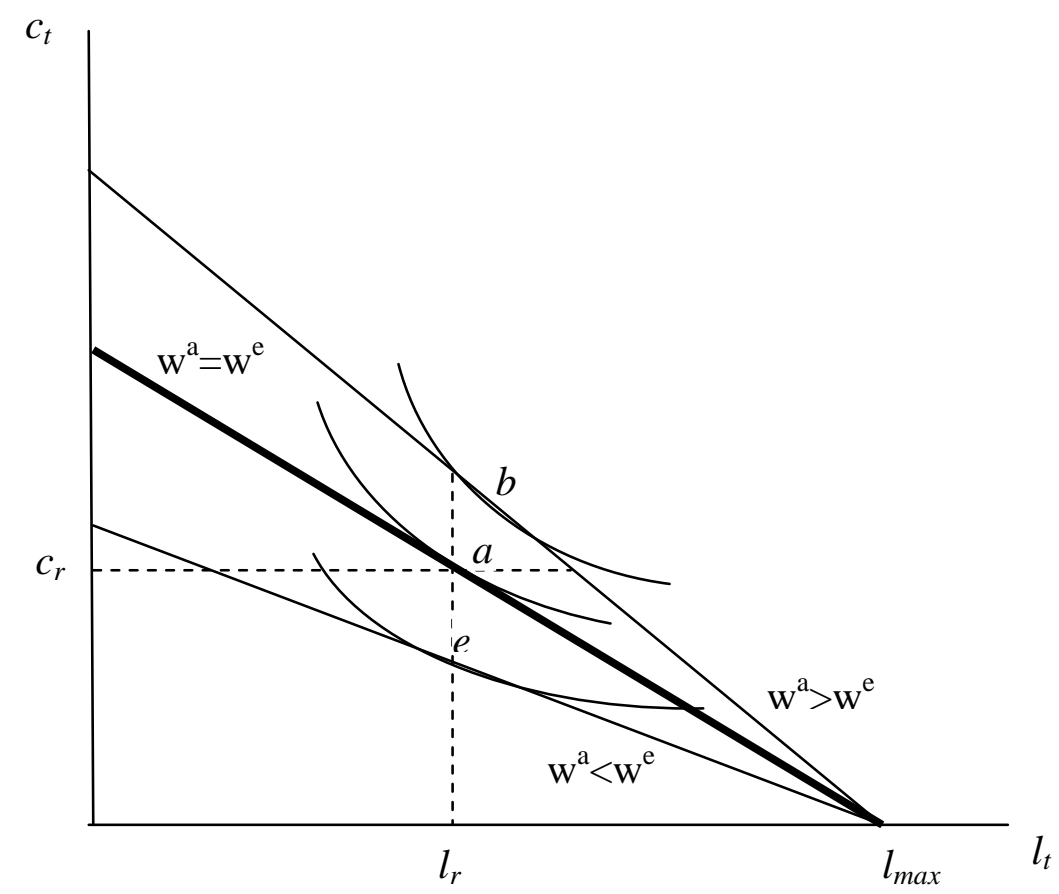

Figure 8. Reference-dependent preferences of a paua diver. 


\begin{tabular}{|c|c|c|c|c|c|}
\hline & Mean & Median & Std. Dev. & Min & Max \\
\hline \multicolumn{6}{|l|}{ PAU 5A $(n=3184)$} \\
\hline Hours dived & 5.0 & 5 & 1.9 & 0 & 11.4 \\
\hline Total catch (kg) & 226 & 200 & 146 & 0 & 1010 \\
\hline $\begin{array}{l}\text { Wage (NZ\$ per } \\
\text { hour })^{\mathrm{a}}\end{array}$ & 167 & 154 & 89 & 0 & 1314 \\
\hline ACE (kg) & 19244 & 11831 & 16637 & 0 & 49460 \\
\hline $\begin{array}{l}\text { \# dive occasions per } \\
\text { diver }\end{array}$ & 55 & 44 & 43 & 1 & 143 \\
\hline $\begin{array}{l}\text { \# dive occ. per diver } \\
\text { per annum }\end{array}$ & 14 & 13 & 9 & 1 & 35 \\
\hline \multicolumn{6}{|l|}{ PAU 5B $(n=3361)$} \\
\hline Hours dived & 4.7 & 5 & 1.9 & 0 & 10.0 \\
\hline Total catch (kg) & 138 & 120 & 100 & 2 & 1400 \\
\hline Wage (NZ\$ per hour) & 113 & 93 & 80 & 1 & 1657 \\
\hline ACE (kg) & 7704 & 6876 & 4711 & 0 & 16976 \\
\hline $\begin{array}{l}\text { \# dive occasions per } \\
\text { diver }\end{array}$ & 96 & 65 & 83 & 1 & 255 \\
\hline $\begin{array}{l}\text { \# dive occ. per diver } \\
\text { per annum }\end{array}$ & 25 & 19 & 21 & 1 & 71 \\
\hline \multicolumn{6}{|l|}{ PAU 5D (n=4263) } \\
\hline Hours dived & 4.3 & 4 & 1.7 & 0 & 10.0 \\
\hline Total catch (kg) & 67 & 56 & 45 & 1 & 149 \\
\hline Wage (NZ\$ per hour) & 105 & 93 & 94 & 0 & 4465 \\
\hline ACE (kg) & 8947 & 7199 & 6115 & 120 & 21022 \\
\hline $\begin{array}{l}\text { \# dive occasions per } \\
\text { diver }\end{array}$ & 67 & 61 & 58 & 1 & 209 \\
\hline $\begin{array}{l}\text { \# dive occ. per diver } \\
\text { per annum }\end{array}$ & 18 & 15 & 14 & 1 & 62 \\
\hline
\end{tabular}

${ }^{\mathrm{a}}$ We assume a flat, stable price of 3.7 per kg (in $2006 \mathrm{NZ}$ dollars), for all divers.

Table 1. Summary statistics 
Table 2. Composition of ACE holders and divers.

\begin{tabular}{|c|c|c|c|}
\hline & PAU 5A & PAU 5B & PAU 5D \\
\hline Total \# ACE holders in dataset & 30 & 32 & 32 \\
\hline Total \# divers in dataset & 341 & 258 & 442 \\
\hline Mean \# ACE holders per year & 20 & 22 & 24 \\
\hline Mean \# divers per year & 115 & 88 & 140 \\
\hline Mean \# ACE holders per diver & 1.3 & 1.2 & 1.2 \\
\hline Mean \# divers per ACE holder & 14.6 & 9.9 & 17.4 \\
\hline Mean \# years per ACE holder & 3.3 & 3.5 & 3.7 \\
\hline Mean \# years per diver & 1.7 & 1.7 & 1.6 \\
\hline $\begin{array}{l}\text { Mean \# years per diver } \\
\text { (experienced diver subset: divers active }>1 \\
\text { year) }\end{array}$ & 3.1 & 3.4 & 3.3 \\
\hline
\end{tabular}


Table 3. Temporal work pattern of paua divers*.

\begin{tabular}{lccc}
\hline & PAU 5A & PAU 5B & PAU 5D \\
\hline mean \# months per annum. & $2.3(1)$ & $2.2(1)$ & $2.4(1)$ \\
experienced diver subset & $4.1(4)$ & $3.8(3)$ & $4.4(4)$ \\
\hline mean \# dive occasions in month & $2.3(2)$ & $3.0(2)$ & $2.4(2)$ \\
experienced diver subset & $2.7(2)$ & $3.9(3)$ & $2.8(2)$ \\
\hline mean \# elapsed days in month & $1.6(0)$ & $1.6(0)$ & $2.5(0)$ \\
experienced diver subset & $1.7(0)$ & $1.6(0)$ & $2.5(0)$ \\
\hline
\end{tabular}

*Median values shown in parenthesis

Table 4. Divers per vessel.

\begin{tabular}{lrrrr}
\hline & Mean & Std. Dev. & Min & Max \\
\hline PAU 5A (n=1052) & & & & \\
\hline Divers per vessel & 3 & 1.4 & 1 & 10 \\
Deviation catch (kg) & 16.8 & 35 & 0 & 322 \\
Deviation hours & 0.04 & 0.3 & 0 & 2.8 \\
\hline PAU 5B (n=1916) & & & & \\
\hline Divers per vessel & 1.8 & 0.9 & 1 & 9 \\
Deviation catch (kg) & 7.2 & 25.6 & 0 & 650 \\
Deviation hours & 0.03 & 0.2 & 0 & 2.5 \\
\hline PAU 5D (n=1892) & & & & \\
\hline Divers per vessel & 2.3 & 1 & 1 & 8 \\
Deviation catch (kg) & 7.2 & 18.1 & 0 & 240 \\
Deviation hours & 0.04 & 0.2 & 0 & 3 \\
\hline
\end{tabular}


Table 5. OLS log hours worked for PAU 5A, 5B and 5D.

\begin{tabular}{|c|c|c|c|}
\hline & PAU 5A & PAU 5B & PAU 5D \\
\hline \multicolumn{4}{|c|}{ Explanatory var } \\
\hline Log wage & $-7.229 * *$ & $-4.041 * *$ & $8.802 * *$ \\
\hline Log wage^2 & $1.208^{* *}$ & $0.660 * *$ & $-0.055^{* *}$ \\
\hline Log wage^3 & $-0.062 * *$ & $-0.035 * *$ & - \\
\hline $\log A C E$ & $0.019 * *$ & $0.120^{* *}$ & $0.033 *$ \\
\hline \multicolumn{4}{|l|}{ Dummy var } \\
\hline Excellent $^{\mathrm{i}}$ & $0.105 * *$ & $0.180 * *$ & $0.214^{* *}$ \\
\hline Good $^{\mathrm{i}}$ & $0.039 *$ & $-0.060 *$ & $0.072 * *$ \\
\hline Average $^{\mathrm{i}}$ & (dropped) & (dropped) & (dropped) \\
\hline Poor $^{\mathrm{i}}$ & $-0.185^{* *}$ & $-0.234 * *$ & $-0.297 * *$ \\
\hline Very poor ${ }^{i}$ & $-0.539 * *$ & $-0.320 * *$ & $-0.573 * *$ \\
\hline Unreported $^{\mathrm{i}}$ & 0.052 & -0.036 & $-0.111^{* *}$ \\
\hline Monday & -0.037 & 0.053 & $-0.075^{* *}$ \\
\hline Tuesday & $-0.065^{*}$ & 0.029 & $0.065^{* *}$ \\
\hline Wednesday & $-0.074 * *$ & 0.037 & 0.028 \\
\hline Thursday & $-0.151 * *$ & 0.014 & -0.049 \\
\hline Friday & $-0.179 * *$ & $-0.104 * *$ & 0.008 \\
\hline Saturday & -0.024 & 0.010 & 0.045 \\
\hline Sunday & (dropped) & (dropped) & (dropped) \\
\hline January & $0.315^{* *}$ & $0.174 * *$ & $0.148 * *$ \\
\hline February & $0.344^{* *}$ & 0.013 & $0.167 * *$ \\
\hline March & $0.444^{* *}$ & $0.073^{*}$ & $0.140 * *$ \\
\hline April & $0.367 * *$ & $0.106^{*}$ & $0.258 * *$ \\
\hline May & $0.260 * *$ & 0.063 & $0.238 * *$ \\
\hline June & $0.302 * *$ & 0.060 & 0.040 \\
\hline July & (dropped) & (dropped) & (dropped) \\
\hline August & $0.229 * *$ & 0.057 & $0.182 * *$ \\
\hline September & $0.221^{* *}$ & -0.091 & $0.080 *$ \\
\hline October & $0.415^{* *}$ & $0.113^{* *}$ & $0.161 * *$ \\
\hline November & $0.368 * *$ & $0.080 * *$ & $0.176^{* *}$ \\
\hline December & $0.417 * *$ & $0.111 * *$ & 0.025 \\
\hline Year02 & $0.118^{* *}$ & $0.065^{* *}$ & $0.125 * *$ \\
\hline Year03 & $0.133^{* *}$ & $0.123^{* *}$ & $0.267 * *$ \\
\hline Year04 & 0.044 & $0.098 * *$ & $0.201 * *$ \\
\hline Year05 & 0.025 & 0.047 & $0.192 * *$ \\
\hline Year06 & (dropped) & (dropped) & (dropped) \\
\hline Constant & $13.570 * *$ & $8.325 * *$ & $-2.071 * *$ \\
\hline \multicolumn{4}{|l|}{ Model stat } \\
\hline Adjusted $\mathrm{R}^{2}$ & 0.173 & 0.117 & 0.135 \\
\hline Observations & 3,178 & 3,312 & 4,259 \\
\hline
\end{tabular}

** Significant at 5\% significance level.

* Significant at $10 \%$ significance level.

${ }^{\mathrm{i}}$ Weather conditions. 
Table 6. Split sample estimations.

\begin{tabular}{|c|c|c|}
\hline & Vessels with $>1$ diver & Vessels with 1 diver \\
\hline PAU 5A & $(n=988)$ & $(n=64)$ \\
\hline Log wage & $-10.349 * *$ & $8.086^{* *}$ \\
\hline Log wage^2 & $1.699 * *$ & $-0.497 * *$ \\
\hline $\log _{\text {wage }} \wedge 3$ & $-0.086 * *$ & - \\
\hline PAU 5B & $(\mathrm{n}=1,002)$ & $(\mathrm{n}=914)$ \\
\hline Log wage & $-17.604^{* *}$ & $-5.619 * *$ \\
\hline Log wage $^{\wedge} 2$ & $2.613 * *$ & $0.872^{* *}$ \\
\hline Log wage^3 & $-0.128 * *$ & $-0.043^{* *}$ \\
\hline PAU 5D & $(n=1,446)$ & $(n=444)$ \\
\hline Log wage & $1.345^{* *}$ & $3.283 * *$ \\
\hline Log wage^ ${ }^{\wedge}$ & $-0.084 * *$ & $-0.203^{* *}$ \\
\hline Log wage^^3 & - & - \\
\hline
\end{tabular}

** Significant at 5\% significance level. 
Table 7. Correlation coefficients between day $t$ and day $t+j$.

\begin{tabular}{lrrr}
\hline Day t & PAU & PAU 5B & PAU 5D \\
& 5A & & Log \\
\hline $\begin{array}{l}\text { Same } \\
\text { area }\end{array}$ & Log \\
hours & 0.27 & hours & Log \\
Day t+1 & $(416)$ & 0.30 & hours \\
(obs) & 0.41 & $(290)$ & 0.31 \\
\hline Day t+2 & $(47)$ & 0.25 & $(652)$ \\
(obs) & - & $(36)$ & 0.09 \\
\hline Day t+3 & & - & $(121)$ \\
(obs) & & & $(31)$ \\
\hline
\end{tabular}

\begin{tabular}{lrrr} 
Any area & $\begin{array}{r}\text { Log } \\
\text { hours }\end{array}$ & $\begin{array}{r}\text { Log } \\
\text { hours }\end{array}$ & $\begin{array}{r}\text { Log } \\
\text { hours }\end{array}$ \\
\hline Day t+1 & 0.18 & 0.44 & 0.29 \\
(obs) & $(1,263)$ & $(1,337)$ & $(1,355)$ \\
\hline Day t+2 & 0.22 & 0.25 & 0.06 \\
(obs) & $(496)$ & $(538)$ & $(493)$ \\
\hline Day t+3 & 0.22 & 0.15 & 0.06 \\
(obs) & $(151)$ & $(203)$ & $(189)$ \\
\hline Day $\mathbf{t + 4}$ & 0.20 & 0.37 & 0.07 \\
(obs) & $(28)$ & $(76)$ & $(63)$ \\
\hline Day $\mathbf{t + 5}$ & - & 0.65 & -0.37 \\
(obs) & & $(34)$ & $(20)$ \\
\hline
\end{tabular}


Table 8. Split sample OLS regression of (log) hours on (log) hours target and (log) revenue target.

\begin{tabular}{l|c|c}
\hline & Split sample: low wage & Split sample: high wage \\
\hline PAU 5A & $0.261^{* *}$ & $0.209^{* *}$ \\
\hline Hours target & 0.033 & $0.071^{* *}$ \\
Income target & 976 & 911 \\
no. of obs. & 0.05 & 0.06 \\
adj. $R^{2}$ & & \\
\hline PAU 5B & $0.487^{* *}$ & $0.750^{* *}$ \\
\hline Hours target & -0.037 & -0.027 \\
Income target & 1,283 & 1,063 \\
No. of obs. & 0.18 & 0.21 \\
Adj. $R^{2}$ & & $0.317^{* *}$ \\
\hline PAU 5D & $0.350^{* *}$ & -0.009 \\
\hline Hours target & -0.021 & 1,181 \\
Income target & 1,331 & 0.06 \\
No. of obs. & 0.07 & \\
Adj. $R 2$ & & \\
\hline
\end{tabular}

** Significant at $5 \%$ significance level. 


\section{Appendix}

\section{A1. Measurement error}

Measurement error can constitute a problem. It should be noted that all quantities of paua received and processed by licensed fish receivers are reported to the Ministry of Fisheries independently so as to verify harvest records. This limits the incentive to under- or over report as is often the case with valuable fisheries. In addition, New Zealand legislation takes a tough line on fisheries-related fraud where paua divers are subject to regular random checks and heavy financial fines if reporting requirements are not met (Fisheries Act 1986).

Farber (2005) expresses concern about regressing hours worked on a wage measure that is computed using the reciprocal of hours, leading to what he calls a division bias. Misspecifications or measurement errors in the amount of catch or hours reported can lead to spurious elasticities, for example, understated hours would lead to high hours-low wage observations and vice versa. Camerer et al. (1997) use the average daily wage of other workers driving on the same day as an instrument, an approach Farber (2005) criticises due to the possibility of the presence of calendar date effects on wage that are also correlated with labour supply conditional on the wage. Calendar date effects are not important for the labour supply decision of paua divers but, as discussed, underwater visibility effects are. However, with a median of only 3-4 divers active on any of the days of reported dive occasions within the whole of the QMA and a median of 2-3 divers within any particular statistical area, the number of divers participating on any given day throughout the year is very low implying there are no significant weather effects that are correlated with labour supply conditional on the wage. 
We calculate the median wage of all divers by day and area and use this median wage as an instrumental variable to account for potential measurement errors. Table A1 shows OLS regression results with and without diver fixed effects when regressing log hours on the log median wage. Weather dummies, day of the week dummies and yearly dummies are included to increase the fit of the model but are not shown in Table A1. Overall, the results do not differ qualitatively in terms of the implied wage elasticities from the results in table 5. Note all coefficients including diver fixed effects are not significant in PAU 5B and 5D.

Table A1. Log Median Wage in PAU 5A, PAU 5B and PAU 5D.

PAU 5A PAU 5B

PAU 5D

OLS regression

Log median wage

$-10.985^{* *}$

$-14.358 * *$

$-6.403 * *$

Log median wage ${ }^{\wedge} 2$

1.806**

$2.215^{* *}$

$0.936 * *$

Log median wage $\wedge 3$

$-0.092 * *$

$-0.111^{* *}$

$-0.047 * *$

Adjusted $\mathbf{R}^{2}$

0.189

0.185

0.135

Diver fixed effects

Log median wage

$-8.937 * *$

$-9.712^{* *}$

$-6.192 * *$

Log median wage $\wedge 2$

1.458**

$1.513 * *$

$0.955 * *$

Log median wage $\wedge 3$

$-0.074 * *$

$-0.077^{* *}$

$-0.048 * *$

Adjusted $\mathbf{R}^{2}$

0.188

0.168

0.137

** Significant at 5\% significance level.

* Significant at 10\% significance level. 


\section{A2. Diver experience}

Diver experience may play a role in terms of observed wage elasticities. The paua resource has been adopted into the ITQ system as far back as 1986, but ACE was only introduced on the 1 October 2001, which coincides with the start of our datasets. We have no information as to how many divers, and if any at all, had been diving prior to 2001 so it is difficult to ascertain the level of experience of any participating diver. However, there are marked differences in terms of the number of diving occasions reported throughout the time period of our datasets.

Referring back to the summary statistics in table 1 , on average divers have reported 55 diving occasions within the time period of 2001-02 to 2005-06 in PAU 5A, 96 occasions in PAU 5B and 67 occasions in PAU 5D. Assuming the lowest quartile of the number of dive occasions by diver represents inexperienced divers, while the three upper quartiles experienced divers, we re-run the regressions for the three QMAs. No significant difference in the shape and magnitude of the derived wage elasticity according to equation (3) is found. Log wage, log wage squared and log wage cubed are less significant for inexperienced divers in PAU 5D but otherwise the observed behaviour of divers in response to changes in the wage rate are relatively stable across levels of experience and QMA.

Wage elasticities have also been estimated for the experienced diver subset identified in tables 2 and 3, i.e. the regressions are run including only divers who are active for more than one year. Again, no significant changes in the shape and magnitude of the derived wage elasticity are found. 